\title{
CLINICO-HAEMATOLOGICAL AND BIOCHEMICAL PROFILE OF DIMORPHIC ANAEMIA WITH BONE MARROW STUDY
}

\author{
Sonu Rawat', Rajni Choudhary², R. K. Nigam ${ }^{3}$ \\ ${ }^{1}$ Resident Medical Officer, Department of Pathology, Gandhi Medical College, Bhopal, Madhya Pradesh. \\ ${ }^{2}$ Associate Professor, Department of Pathology, Gandhi Medical College, Bhopal, Madhya Pradesh. \\ 3Professor, Department of Pathology, Gandhi Medical College, Bhopal, Madhya Pradesh.
}

\section{BACKGROUND}

ABSTRACT

Dimorphic anaemia is very common in India. Dimorphism indicates the presence of two distinct populations of red cells. The term is most often applied when there is one population of hypochromic, microcytic cells and another population of normochromic cells, either normocytic or macrocytic.

Aims and Objectives-

1. Dimorphic anaemia has been studied, because treatment may be ineffective if the dual deficiency is not diagnosed.

2. To correlate and compare the clinico-haematological, biochemical parameters with bone marrow study.

3. To find out the clinical and haematological features of severe anaemia with bone marrow study.

\section{MATERIALS AND METHODS}

This descriptive study included 51 cases of dimorphic anaemia to evaluate association of biochemical profile of dimorphic anaemia with bone marrow study. Data collected from case files, patient history, clinical profile, peripheral blood findings, haematological parameters, bone marrow aspiration and biochemical parameters.

\section{RESULTS}

In our study, dimorphic anaemia (DA) was mostly found in 15 - 30 years of age. The male-to-female ratio was 1.5: 1 in our study. The most common clinical presentation was pallor and generalised weakness $(100 \%)$ followed by easy fatigability $(72.5 \%)$, fever (54.90\%), altered behaviour (19.6\%) and tingling (8\%) are found. Bleeding (13.7\%), itching and red spots (13.7\%) are found in patients having thrombocytopenia. DA was found mostly in vegetarians $(62.7 \%)$. The mean haemoglobin was $6.6 \mathrm{gm} / \mathrm{dL}$. Splenomegaly and hepatomegaly were present in $35.2 \%$ and $23.5 \%$ respectively. There was complete correlation between three parameters in $8 / 51(15.68 \%)$ cases only.

\section{CONCLUSION}

Bone marrow examination provides rapid and cost-effective investigation for confirming the diagnosis of dimorphic anaemia by reliably assessing the iron stores. Serum ferritin is more specific in predicting the iron deficiency. Serum vitamin B12 and serum folate are also specific, but not sensitive.

\section{KEY WORDS}

Bone Marrow, Dimorphic Anaemia, Ferritin, Folate, Vitamin B-12.

HOW TO CITE THIS ARTICLE: Rawat S, Choudhary R, Nigam RK. Clinico-haematological and biochemical profile of dimorphic anaemia with bone marrow study. J. Evolution Med. Dent. Sci. 2018;7(19):2338-2341, DOI: 10.14260/jemds/2018/527

\section{BACKGROUND \\ Anaemia is defined as a reduction in haemoglobin} concentration below the level, which is expected for healthy person of same age and sex and in the same environment. Adequate oxygen cannot be delivered to various organs and tissues due to low oxygen carrying capacity of blood.(1)

In the United States the prevalence of anaemia in population studies of healthy, non-pregnant people depends on the $\mathrm{Hb}$ concentration chosen for the lower limit of normal values. The World Health Organisation (WHO) chose $12.5 \mathrm{~g} / \mathrm{dL}$ for both adult males and females.

'Financial or Other Competing Interest': None.

Submission 13-03-2018, Peer Review 17-04-2018,

Acceptance 24-04-2018, Published 07-05-2018.

Corresponding Author:

Dr. Rajni Choudhary,

Associate Professor,

Department of Pathology,

Gandhi Medical College,

Bhopal, Madhya Pradesh.

E-mail: rajnichoudhary49@gmail.com

DOI: $10.14260 /$ jemds $/ 2018 / 527$
In the United States, limits of $13.5 \mathrm{~g} / \mathrm{dL}$ for men and 12.5 $\mathrm{g} / \mathrm{dL}$ for women are probably more realistic. In India, anaemia is considered below $11.0 \mathrm{~g} / \mathrm{dL}$ in females and $13.0 \mathrm{~g} / \mathrm{dL}$ in males.

Internationally, anaemia caused by iron deficiencies is the most common nutritional disorder.

In underprivileged countries, the prevalence of anaemia is found to be 2 - 5 times greater than that in the United States. Although, geographic diseases such as sickle cell anaemia, thalassemia, malaria, hookworm and chronic infections are responsible for a portion of the increase, nutritional factors with iron deficiency and folic acid deficiency play major roles in the increased prevalence of anaemia.

In developing countries, about $40 \%$ of preschool children and $50 \%$ of pregnant women are estimated to be anaemic. $20 \%$ of maternal deaths can be contributed to anaemia.(2) Anaemia affects approximately $17 \%$ in industrialised countries. Nutritional megaloblastic anaemia in children occurs commonly among undernourished or malnourished societies of tropical and subtropical countries.(3) 
Dimorphic anaemia (DA) is defined by two distinct red cell populations- one is hypochromic, microcytic cells and another of normochromic cells, either normocytic or macrocytic.

DA is very common in India. It is estimated that $30 \%$ of the world's population is anaemic. In India, according to ICMR (district nutrition survey data report), prevalence of anaemia is $84.2 \%$ with severe anaemia in $13.1 \%$ population.(4)

Certain races and ethnic groups have an increased prevalence of genetic factors associated with certain anaemias. Race is a factor in nutritional anaemias and anaemia associated with untreated chronic illnesses, eg. malaria, tuberculosis, acquired immunodeficiency syndrome.

Severe genetically acquired anaemias (eg. sickle cell disease, thalassemia, Fanconi syndrome) were more commonly found in children, because they did not survive to adulthood.(5)

Overall, anaemia is twice as prevalent in females as in males. This difference is significantly greater during the childbearing age due to pregnancies and menses. In the younger age groups, males have a higher incidence of acute anaemia from traumatic causes.(5)

Acute anaemia has a bimodal frequency distribution, affecting mostly young adults and persons in their late fifties. Causes among young adults include trauma, gastrointestinal bleeding, menstrual and ectopic bleeding and problems of acute haemolysis.(5)

Neoplasia increases in prevalence with each decade of life and produce anaemia from bleeding, from the invasion of bone marrow with tumour or from the development of anaemia associated with chronic disorders.(5)

Dimorphic anaemia can occur when iron deficiency anaemia responds to iron therapy, after the transfusion of normal blood to a patient with hypochromic anaemia, sideroblastic anaemia, refractory anaemia, macrocytic anaemia, post transfusion, unmasking of iron deficiency following treatment of megaloblastic anaemia, delayed transfusion reactions and dual deficiency of iron and either vitamin B12 or folic acid,(4) which is the focus of our study.

A dimorphic picture on peripheral blood smear is not correlated with bone marrow iron level and S. ferritin level. Iron may be reduced, normal or increased on bone marrow examination. Biochemical parameters may be fluctuated.

This descriptive study was planned to correlate and compare the clinico-haematologic, biochemical parameters with bone marrow study in cases diagnosed as DA on peripheral smear finding.

\section{MATERIALS AND METHODS}

This descriptive study period was conducted in the Department of Pathology, Gandhi Medical College, Bhopal. 51 patients who were diagnosed as dimorphic anaemia on peripheral blood smear and who consented for bone marrow aspiration with relevant biochemical investigations were included in the study.

The study included all cases of anaemia having haemoglobin less than $11 \mathrm{gm} / \mathrm{dL}$. Patients with recent blood transfusion, treatment with haematinics, pregnancy and with underlying haemoglobinopathies are excluded.

\section{Ethical Clearance}

The study was approved by Institutional Ethics Committee of Gandhi Medical College, Bhopal (MP) with letter no. 762527/MC/IEC/2016 dated 03/03/16.

\section{Grading of Anaemia}

The patients were then grouped as mild (10 - 10.9 gm\%), moderate ( 7 - 9.9 gm $\%)$ and severe $(<7$ gm $\%)$ anaemia based on their initial haemoglobin level. Patients were recorded in proforma including detailed history, clinical profile, haematological parameters, bone marrow aspiration and biochemical parameters.

\section{Haematological Parameters}

Blood sample was collected for complete blood counts using automated 3 and 5 part Mindray counter machine. Leishman stained smears of PBS and BMA were examined. Iron store were graded in Perls' stained bone marrow smear.

\section{Estimation of Biochemical Parameters}

Blood sample in a plain vial was collected. After centrifugation, the clear supernatant serum was collected. It was used for the estimation of serum vitamin B12, folate, ferritin by the chemiluminescence method.

\section{Statistical Analysis}

All analysis was done using Epi Info version 7.2.1.0. Qualitative data was expressed as number and percentage. Quantitative data was expressed as mean. Qualitative data was analysed using chi-square test. Correlation between ordinal variables was determined by calculating Spearman rank order correlation coefficient. $\mathrm{P}$ value $<0.05$ was taken as statistically significant.

\section{RESULTS}

\begin{tabular}{|c|c|c|c|c|c|c|}
\hline Age Group & Male & & Female & & Total & \\
\hline & $\mathrm{N}$ & $\%$ & $\mathrm{~N}$ & $\%$ & $\mathrm{~N}$ & $\%$ \\
\hline$\leq 15$ years & 5 & $16.1 \%$ & 4 & $20 \%$ & 9 & $17.6 \%$ \\
\hline $\begin{array}{c}16-30 \\
\text { years }\end{array}$ & 13 & $41.9 \%$ & 7 & $35 \%$ & 20 & $39.2 \%$ \\
\hline $\begin{array}{c}31-45 \\
\text { years }\end{array}$ & 7 & $22.9 \%$ & 6 & $30 \%$ & 13 & $25.5 \%$ \\
\hline $\begin{array}{c}46-60 \\
\text { years }\end{array}$ & 5 & $16.1 \%$ & 1 & $5 \%$ & 6 & $11.8 \%$ \\
\hline$>60$ years & 1 & $3.2 \%$ & 2 & $10 \%$ & 3 & $5.9 \%$ \\
\hline Total & 31 & $100 \%$ & 20 & $100 \%$ & 51 & $100 \%$ \\
\hline
\end{tabular}

Chi-square $=2.743$ with 4 degrees of freedom; $\mathrm{P}=0.602$ (NS). Maximum number of cases (64.7 \%) were found in 16-45 years of age group (Age range: 5-70 years) with male predominance.

\begin{tabular}{|c|c|c|}
\hline Dietary Habit & $\mathbf{N}$ & Percentage \\
\hline Vegetarian & 32 & $62.7 \%$ \\
\hline Non-Vegetarian & 19 & $37.3 \%$ \\
\hline Total & 51 & $100 \%$ \\
\hline \multicolumn{3}{|c|}{$\begin{array}{c}\text { Table 2. Distribution of Study Subjects according } \\
\text { to their Dietary Habit }\end{array}$} \\
\hline
\end{tabular}

Maximum number of cases were vegetarian- $62.7 \%$

\begin{tabular}{|c|c|c|}
\hline Religion & N & Percentage \\
\hline Hindu & 43 & $84.3 \%$ \\
\hline Muslim & 8 & $15.7 \%$ \\
\hline Total & $\mathbf{5 1}$ & $\mathbf{1 0 0 \%}$ \\
\hline \multicolumn{2}{|c|}{ Table 3. Distribution of Study Subjects according } \\
to their Religion
\end{tabular}

Maximum patients were Hindu. 


\begin{tabular}{|c|c|c|}
\hline Clinical Features & $\mathbf{N}$ & Percentage \\
\hline Paleness of skin & 51 & $100 \%$ \\
\hline Generalised weakness & 51 & $100 \%$ \\
\hline Easy fatigability & 37 & $72.5 \%$ \\
\hline Fever & 28 & $54.9 \%$ \\
\hline Altered behaviour & 10 & $19.6 \%$ \\
\hline Tingling, numbness & 8 & $16.9 \%$ \\
\hline $\begin{array}{l}\text { Bleeding from nose and } \\
\text { rectum }\end{array}$ & 7 & $13.7 \%$ \\
\hline Itching, red spots & 7 & $13.7 \%$ \\
\hline \multicolumn{3}{|c|}{$\begin{array}{c}\text { Table 4. Distribution of Clinical Symptoms and Signs i } \\
\text { Study Subjects }\end{array}$} \\
\hline
\end{tabular}

Maximum no. of cases present with symptoms of pallor and generalised weakness $(100 \%)$ followed by easy fatigability $(72.5 \%)$, fever (54.9\%), altered behaviour (19.6\%) and tingling sensation (8\%) were found in vitamin B12 deficiency. Bleeding (13.7\%), itching and red spots (13.7\%) were attributed due to thrombocytopenia.

\begin{tabular}{|c|c|c|}
\hline Radiological Findings & $\mathbf{N}$ & Percentage \\
\hline Splenomegaly & 18 & $35.3 \%$ \\
\hline Hepatomegaly & 12 & $23.5 \%$ \\
\hline \multicolumn{3}{|c|}{ Table 5. Radiological Findings in Study Subject } \\
\hline
\end{tabular}

In our study, cases of splenomegaly were $35.3 \%$ and cases of hepatomegaly were $23.5 \%$.

\begin{tabular}{|c|c|c|c|c|c|c|}
\hline $\begin{array}{c}\text { Haemoglobin } \\
\text { Level }\end{array}$ & Male & Female & & Total & \\
\hline & $\mathrm{N}$ & $\%$ & $\mathrm{~N}$ & $\%$ & $\mathrm{~N}$ & $\%$ \\
\hline$<7 \mathrm{gm} \%$ & 20 & $64.5 \%$ & 12 & $60 \%$ & 32 & $62.7 \%$ \\
\hline $7-9.9 \mathrm{gm} \%$ & 9 & $29 \%$ & 7 & $35 \%$ & 16 & $31.4 \%$ \\
\hline $10-10.9 \mathrm{gm} \%$ & 2 & $6.5 \%$ & 1 & $5 \%$ & 3 & $5.9 \%$ \\
\hline Total & $\mathbf{3 1}$ & $\mathbf{1 0 0 \%}$ & $\mathbf{2 1}$ & $\mathbf{1 0 0} \%$ & $\mathbf{5 1}$ & $\mathbf{1 0 0} \%$ \\
\hline Table 6. Distribution of Study Subject according \\
to Severity of Anaemia \\
\hline
\end{tabular}

Chi-square $=0.221$ with 2 degrees of freedom; $\mathrm{P}=0.895$ (NS). Severe anaemia $62.7 \%$, moderate anaemia $31.4 \%$ and mild anaemia $5.9 \%$ with male predominance. In males $64.5 \%$ and in females $60 \%$ of severe anaemia were found.

\begin{tabular}{|c|c|c|c|c|}
\hline $\begin{array}{c}\text { Bone } \\
\text { Marrow }\end{array}$ & $\begin{array}{c}\text { Serum } \\
\text { Ferritin }\end{array}$ & $\begin{array}{c}\text { Correlation } \\
\text { between BM and } \\
\text { S. Ferritin (\%) }\end{array}$ \\
\hline Status & Low & Normal & High & \\
\hline Low (31) & 22 & 4 & 5 & $70.90 \%$ \\
\hline $\begin{array}{c}\text { Normal } \\
(15)\end{array}$ & 0 & 13 & 2 & $86.6 \%$ \\
\hline High (05) & 0 & 4 & 1 & $20 \%$ \\
\hline \multicolumn{7}{|c|}{ Table 7. Distribution of Bone Marrow Iron and S. Ferritin } \\
Level Study
\end{tabular}

Spearman rank order correlation coefficient $r=0.629$; $\mathrm{p}<0.001$ (S). Bone marrow iron decreased in $60.78 \%$ cases and serum ferritin decreased in $43.1 \%$ cases. The values of decreased BM iron and decreased S. ferritin are correlated to each other $70.9 \%$.

\begin{tabular}{|c|c|c|c|c|c|c|}
\hline Parameter & Low & & Normal & & High & \\
\hline & $\mathrm{N}$ & $\%$ & $\mathrm{~N}$ & $\%$ & $\mathrm{~N}$ & $\%$ \\
\hline BM Iron & 31 & 60.8 & 15 & 29.4 & 5 & 9.8 \\
\hline S. ferritin & 22 & 43.1 & 21 & 41.2 & 8 & 15.7 \\
\hline S. folate & 15 & 29.4 & 29 & 56.9 & 7 & 13.7 \\
\hline S. B12 & 17 & 33.3 & 25 & 49.0 & 9 & 17.6 \\
\hline
\end{tabular}

Correlation of S. ferritin with BMA and PBS are $43.1 \%$. S. vitamin B-12 with BMA, PBS are $33.3 \%$ and S. folate with BMA, PBS are $29.4 \%$ which showed megaloblastosis in bone marrow pictures. All were found decreased in only $15.68 \%$ cases. $3.92 \%$ cases showed decreased S. ferritin value and increased Vit. B-12/ folate.

\section{DISCUSSION}

In our study period of 18 months, there were $52.4 \%$ cases of anaemia, of which dimorphic anaemia was found to be $8.3 \%$ of the total anaemic cases in all age groups. Riwan Ather et al(4) found DA in $12.5 \%$ of cases, which is similar to our study. In India dietary habits are influenced and affected by differences in religion, cultural and socioeconomic status. Majority of patients in our study belonged to low socio-economic status.

The mean age of our patients is 39 years (Age range: 5 - 70 years). $39.2 \%$ of patients in our study were in the age group of 16 - 30 years with male: female ratio of $1.5: 1$. Saira Perwaiz et $\mathrm{al}^{(6)}$ reported the mean age as 38.9 years ( 1 - 80 years) and peak age group was 35 - 50 years. The male-to-female ratio was 1: 1. Jagdish Chandra et al(5) reported peak age less than 2 years (6 months - 12 years), male-to-female ratio was 1.04: 1 .

Male predominance could be due to social pattern in our society, as males get more attention in Indian families resulting in higher access to the hospital.

The most common clinical presentation besides pallor and generalised weakness, which were present in all cases where easy fatigability was (72.5\%) and Fever was (54.9\%).

In our study, DA was found mostly in vegetarians (62.7\%). These findings are similar to Saira Perwaiz et al(6) and Pogura Nagarjuna et al(1) who reported anaemia in $85 \%$ and $60 \%$ vegetarians respectively. It may be due to religious and social issues.

The mean haemoglobin in our study was $6.6 \mathrm{~g} / \mathrm{dL}$. Saira et $\mathrm{al}(6)$ and Iqbal et al(2) reported the mean haemoglobin was $6.8 \mathrm{~g} / \mathrm{dL}$. In Sunil Gomber et al(3) and Jagdish Chandra et al(5) reported haemoglobin was $5.32 \mathrm{~g} / \mathrm{dL}$ and $5.65 \mathrm{~g} / \mathrm{dL}$.

In our study, splenomegaly and hepatomegaly were present in $35.2 \%$ and $23.5 \%$. Amieleena Chhabra et al(1) reported splenomegaly and hepatomegaly were $28.8 \%$ and $53.3 \%$. Sunil Gomber et al(3) reported splenomegaly and hepatomegaly were $21 \%$ and $66 \%$ respectively. Splenomegaly was present in most of the moderate-to-severe anaemic and thrombocytopenic patients.

Eosinophilia was present in $21.5 \%$ cases with complaint of breathlessness. In our study, bone marrow iron stores revealed increase in $9.80 \%$, normal in $29.41 \%$ and depleted in $60.78 \%$ of the patients. Only $5.88 \%$ patients found elevated serum ferritin level, which show decreased bone marrow iron. Ali et al(7) in his study of $27.82 \%$ patients found lack of iron stores. Of these, the serum ferritin was elevated in 20 patients (29\%) despite lack of demonstrable iron in the marrow specimen. They concluded that a low serum ferritin value probably indicates iron depletion, while an elevated value does not exclude that possibility. In our study, they could attribute prior iron therapy and blood transfusion and chronic diseases as cause of increased ferritin.(8)

All 51 cases showed megaloblastosis in the bone marrow. But only 17 cases (33.33\%) had either and low serum VitB12/Folate or both. The rest 34 cases $(66.66 \%)$ had either normal or high Vitamin B12/Folate. So, there was a correlation between bone marrow findings and Vitamin B12/ Folate in 
33.3\% cases only. Serum Folate/ Vitamin-B12 levels are known to be highly labile to the extent that a low serum folate concentration can be rapidly normalised shortly after consumption of a single nutritious folate rich meal.

Our study showed isolated B12 deficiency in 29.4\%, combined deficiency in $33.3 \%$ and isolated folate deficiency was not found. Rizwan Ather et al(4) showed isolated vitamin B-12 deficiency in 10.34\%, isolated folate deficiency in 17.24\% and combined deficiency in $15.5 \%$ of cases. The low percentage of isolated folate deficiency in our study could be due to exclusion of pregnant ladies from this study.(4) There was complete correlation between three parameters in 8/51 $(15.68 \%)$ cases only. Clinically, it is important to know whether the anaemia is due to folate or vitamin B12 or combined deficiency, so that the appropriate treatment may be given.

\section{CONCLUSION}

1. Inadequate dietary intake, overcooking of our food and poor absorption contributing to high prevalence of dimorphic anaemia.

2. Besides medication, foods can alter the parameters, so bone marrow aspiration is better than biochemical profiles for estimation of megaloblastosis.

3. Bone marrow examination provides rapid and costeffective investigation for confirming the diagnosis of dimorphic anaemia by reliably assessing the iron stores, as serum ferritin is more specific in predicting the iron deficiency.

4. Bone marrow aspiration though invasive, can be easily performed, which will give correct diagnosis.

\section{REFERENCES}

[1] Chhabra A, Chandar V, Gupta A, et al. Megaloblastic anaemia in hospitalised children. JIACM 2012;13(3):195-7.

[2] Iqbal SP, Kakepoto GN, Iqbal SP. Vitamin B12 deficiency--a major cause of megaloblastic anaemia in patients attending a tertiary care hospital. J Ayub Med Coll Abbottabad 2009;21(3):92-4.

[3] Gomber S, Kela K, Dhingra N. Clinico-hematological profile of megaloblastic anemia. Indian Pediatr 1998;35(1):55-8.

[4] Athar R, Khonglah Y, Raphael V, et al. Clinicohematologic and biochemical profile of dimorphic anemia with bone marrow study. The Internet Journal of Laboratory Medicine 2014;6(1).

[5] Chandra J, Jain V, Narayan S, et al. From the division of pediatric hematology and biochemistry, Kalawati Saran children's hospital and department of pathology, lady hardinge medical college, New Delhi 110 001, India. Indian Pediatrics 2002;39:453-7.

[6] Islam A. A new bone marrow aspiration needle to overcome the sampling error inherent in the technique of bone marrow aspiration. J Clin Pathol 1983;36(8):954-8.

[7] Ali MA, Luxton AW, Walker WH. Serum ferritin concentration and bone marrow iron stores: a prospective study. Can Med Assoc J 1978;118(8):945-6.

[8] Finberg KE. Iron-refractory iron deficiency anemia. Semin Hematol 2009;46(4):378-86. 